\section{SYMPATHECTOMY IN TREATMENT OF THE CRYOPATHIES}

BY

\section{E. D. TELFORD, F.R.C.S.}

Emeritus Professor of Surgery, University of Manchester

(From the Neurovascular Clinic, Manchester Royal Infirmary)

The cryopathies include conditions such as frostbite, immersion foot and hand, trench and shelter foot. The inclusion of these lesions in one group is justified by the fact that their pathology is identical ; they differ only in the degree of damage. While exposure to cold is no doubt the main factor, prolonged immersion must play an important part. Webster (1942) reports a series of cases, some of them gangrenous, which resulted from prolonged immersion in sea-water at 60 to $70^{\circ} \mathrm{F}$.

The literature is already considerable. The subject has been fully discussed in recent important papers by Ungley (1942, 1943) and Greene (1942). These and other writers insist strongly that in the treatment of these patients the temperature of the damaged parts must be raised with extreme slowness and caution. A too rapid return to normal will be disastrous, especially if it be accelerated by any form of heat. Others have advocated sympathectomy in the immediate treatment. Against this suggestion is the fact that after rescue the chilled areas become notably hyperaemic, and it is in this stage that the local damage appears to increase or at least to become more obvious. It is not easy to see how a sympathectomy is going to act in tissues where so much damage to nerves is already present, and if it did act it could hardly be good practice to increase and prolong the stage of harmful hyperaemia. An analogy can be drawn from plant life. The gardener who has had the misfortune to have a delicate plant frosted would never dream of treating it by exposure to sun or raised temperature or by flooding with tepid water. $\mathrm{He}$ knows that his only chance is to withhold water and to maintain the plant under cool conditions, allowing the temperature to rise only with infinite slowness and patience.

The Sequelae and their Treatment

Although the majority of cases appear to make a good recovery with no, or at the worst trivial, loss of tissue, others continue to suffer from symptoms which are due to a combination of sclerosis and deficient blood supply. The aftertroubles most often found are pain of a burning or tingling type increased by warmth and exertion, persistent indurated swelling, chronic and very painful ulcers of pulps or extremities of digital stumps, loss of movement of fingers and toes, and occasionally a sensitization to cold which results in the Raynaud phenomenon. Hyperhidrosis may also be troublesome. These end-results are in fact those of vascular occlusion, and resemble closely those found in the more chronic types of thromboangiitis obliterans.

It seems reasonable, therefore, to hope that for these later troubles a sympathectomy may offer some prospect of relief. I have during the last five years had the opportunity of treating the later consequences of trauma from cold by preganglionic sympathectomy in five patients. In each of these cases a very gratifying relief of symptoms has been obtained. The patients were all men, of whom four were victims of frostbite-one in the hands and three in the feet-while the fifth was a negro seaman with grave damage to both feet from immersion. Brief notes of two of these cases are as follows.

\section{Notes on Two Cases}

Case 1.-A farm labourer aged 40 had the fingers of both hands frostbitten at his work. They recovered without loss of tissue, but at the end of eighteen months he was quite unable to work owing to chronic and very painful ulcers, together with a most troublesome Raynaud phenomenon. When seen in August, 1938, he could do no outdoor work because of the cyanotic attacks, and was suffering pain and loss of sleep from chronic ulceration of the right index and left ring fingers. A bilateral preganglionic section of the cervico-dorsal chain was done in Sept., 1938. The result was immediately satisfactory. The circulation in the fingers improved and the ulcers healed. The Raynaud phenomenon, though not entirely abolished, was much reduced in frequency and severity. He has since been seen on many occasions, and remains well and in full work.
Case 2.-A negro seaman aged 24 was adrift in an open boat in the North Atlantic during ten days in Nov., 1941. He was landed and was treated for six months in hospital in Newfoundland. In June, 1942, he was seen in this clinic, complaining of pain, ulceration, and inability to walk. Both feet were swollen, hard to the touch, and completely stiff. Tenderness and excessive sweating were noted. All the toes of both feet had been partially shed, and their stumps bore small chronic ulcers; the left fifth toe was gangrenous. He complained of constant burning pain, increased by warmth and attempts to walk. A bilateral lumbar-cord ganglionectomy was done by my colleague Miss Liebert in June, 1942, and resulted in immediate relief of pain, with rapid healing of the ulcers. The gangrenous toe did not improve, and was subsequently amputated, the wound healing readily. He has since continued well and gets about without pain.

These results would seem to indicate that sympathectomy is worth while in the chronic and painful sequelae of the cryopathies.

\section{Conclusion}

In the endeavour to estimate what benefit may result from the operation in any given case recourse may be had to preliminary tests of vascular efficiency-e.g., nerve block or foreign protein. In my experience the best method for the lower extremities is to use a thermo-couple thermometer provided with 8 or 10 leads, each carrying a point for application to the skin. These points are fixed on the areas selected for observation, and a movable plug allows the current from any one point to be recorded by the reflecting galvanometer. The temperatures are recorded with the patient on the theatre table, and at the end of half an hour's observation of temperature a spinal anaesthetic is given and the temperatures again recorded. The normal rise in the feet in a young healthy adult is of the order of 8 to $10^{\circ} \mathrm{C}$., but in cases such as those under discussion a rise of $1^{\circ} \mathrm{C}$. would justify sympathectomy, which can be carried out forthwith. In the upper limb a general vasodilator may be employed, although it may be that, where all fingers appear equally affected, a simple block of the ulnar nerve at the elbow will give sufficient evidence.

\section{REFERENCES}

Greene, R. (1942). Lancet, 2, 695

Ungley, C. C. (1942). Ibid., 2, 447

- (1943). Ibid. 1, 681 .

Webster, D. R. (1942). J. Bone Jt. Surg., 24, 785.

\section{MISUSE OF INTRAVENOUS N.A.B. FOR VINCENT'S INFECTION \\ BY}

\section{ERIC C. O. JEWESBURY, D.M., M.R.C.P., D.P.M.} Acting Squadron Leader, R.A.F.V.R.

Ever since Ehrlich (1910) first reported the use of intravenous arsenic in the treatment of Vincent's angina arsenicals have continued to be advocated for this purpose. To-day, when both the available supply and the cost-of such things deserve special consideration, it is worth while questioning the value of N.A.B. and its allies, particularly when given intravenously, in the treatment of this infection.

The disease, termed "trench mouth" in the last war, is a common accompaniment of wartime conditions, and there still seems to be a fairly widespread impression that in severe cases intravenous N.A.B. is the most potent method of treatment. Since N.A.B., in direct contact with the organisms; has a high spirochaeticidal power, it is at least logical to apply it locally to the lesions in the mouth. But Vincent's infection, unlike syphilis, is a purely local condition, and attempts to isolate fusospirochaetal organisms from the blood stream of infected patients have never been successful. Occasional case reports of Vincent's infection occurring in patients undergoing antisyphilitic treatment have cast further doubt on the efficacy of intramuscular or intravenous arsenic in dealing with the lesions in the mouth

\section{Vincent's Angina after Intravenous Arsenicals}

Thus, Sutton (1924) reported the case of a syphilitic woman who first developed Vincent's ángina eleven days after starting intramuscular injections of sulpharsphenamine. She had many carious teeth, and direct smears obtained from typical lesions 